\title{
In vitro and in silico antioxidant and antiproliferative activity of rhizospheric fungus Talaromyces purpureogenus isolate-ABRF2
}

\author{
Mahendra Kumar Sahu' ${ }^{1}$ Komal Kaushik ${ }^{2,3}$, Amitava Das $^{2,3^{*}}$ and Harit Jha ${ }^{{ }^{*}}$
}

\begin{abstract}
The present study evaluated the potential biological activities of rhizospheric fungi isolated from the Achanakmar Biosphere Reserve, India. Fungus, Talaromyces purpureogenus isolate-ABRF2 from the soil of the Achanakmar biosphere was characterized by using morphological, biochemical and molecular techniques. Fungus was screened for the production of secondary metabolites using a specific medium. The metabolites were extracted using a suitable solvent and each fraction was subsequently evaluated for their antioxidant, antimicrobial, antiproliferative and anti-aging properties. The ethanolic extract depicted the highest antioxidant activity with $83 \%, 79 \%, 80 \%$ and $74 \%$ as assessed by ferric reducing power, 2,2-diphenyl 1-picrylhydrazyl, 2,2'-azino-bis3-ethylbenzthiazoline-6-sulfonic and phosphomolybdenum assays, respectively. Similarly, ethanolic extracts depicted marked antimicrobial activity as compared with standard antibiotics and antifungal agents as well as demonstrated significant antiproliferative property against a panel of mammalian cancer cell lines. Furthermore, different fractions of the purified ethanolic extract obtained using adsorption column chromatography were evaluated for antiproliferative property and identification of an active metabolite in the purified fraction using gas chromatography-mass spectroscopy and nuclear magnetic resonance techniques yielded 3-methyl-4-oxo-pentanoic acid. Thus, the present study suggests that the active metabolite 3-methyl-4-oxo-pentanoic acid extracted from Talaromyces purpureogenus isolate-ABRF2 has a potential antiproliferative, anti-aging, and antimicrobial therapeutic properties that will be further evaluated using in vivo studies in future.
\end{abstract}

Keywords: Talaromyces purpureogenus, Rhizospheric, Antioxidant, Antiproliferative, Anti-aging

\section{Introduction}

Fungi are a major source of metabolites with a wide range of biological and therapeutic activities (Baker and Alvi 2004). The fungal secondary metabolites have been reported as antibiotics, therapeutic agents as well as undesirable immunosuppressant and toxic substances (Miranda et al. 2010). They also show antimicrobial

\footnotetext{
*Correspondence: amitavadas@iict.res.in; harit74@yahoo.co.in 1 Department of Biotechnology, Guru Ghasidas Vishwavidyalaya, Bilaspur, Chhattisgarh 495009, India

${ }^{2}$ Department of Applied Biology, CSIR-Indian Institute of Chemical Technology, Uppal Road, Tarnaka, Hyderabad, TS 500 007, India Full list of author information is available at the end of the article
}

(erythromycin and bacitracin), antiproliferative, antiaging, anti-inflammatory, anticancer (Maheshwari et al. 2017), hypocholesterolemic (Kwon et al. 2002), antifungal (Nikoletti et al. 2007) antiviral (Nishihara et al. 2000) and antioxidant (Gangadevi and Muthumary 2008) activities. The natural antioxidant activity of fungal secondary metabolites thus has a plausible major role in developing therapeutic interventions against cancer and myocardial infarction (Maritim et al. 2003).

The fungal metabolites have been also reported to regulate different metabolic pathways and cellular activities due to pleiotropic action (Badri et al. 2009). Rhizospheric fungi are a major untapped source of novel metabolites 
which have not yet been explored and screened to assess their therapeutic potential. Thus, in the present study, fungi isolated from pristine soil of the Achanakmar Biosphere region (located in central India) were evaluated for their potent biological activities, extraction, and identification of novel secondary metabolites with putative therapeutic potentials using standard biochemical and cell biological approaches. Briefly, the extract of the strain with potent activity was selected and the secondary metabolites were purified by adsorption column chromatography, gas chromatography-mass spectroscopy (GC$\mathrm{MS}$ ) and nuclear magnetic resonance (NMR) techniques which were subsequently evaluated for antioxidant, antimicrobial and antiproliferative activities using in vitro analysis that corroborated well with in silico molecular docking analysis.

\section{Materials and methods Chemicals and reagents}

Potato dextrose agar, potato dextrose broth, and Czapek Dox, malt extract, yeast extract were procured from HiMedia, India. 2,2-diphenyl-1-picrylhydrazyl (DPPH), 2,2' azinobis (3-ethyl benzthiazoline-6-sulphonic acid) (ABTS+), ascorbic acid, potassium persulfate, streptomycin fluconazole were purchased from Sigma-Aldrich, USA. All the reagents and chemicals used were of analytical reagent grade.

\section{Isolation and identification of the fungus}

Different fungal strains were isolated from the rhizospheric soil of Achanakmar Biosphere, Bilaspur, Chhattisgarh, India, by the method as described earlier (Radhika and Rodrigues 2010). The potent fungal isolate was characterized and identified based on morphological characterization using a compound microscope (AXIO SCOPE. A1 HBO 50, Zeiss, Germany) and scanning electron microscope (FEI Nova NanoSEM450, Thermo Fisher USA). Molecular characterization of the identified fungal isolate was performed by partial gene sequencing of the internal transcribed spacer (ITS) regions at a commercial center (Chromous Biotech Pvt. Ltd., Bangalore, India). Briefly, fungal DNA was isolated using a DNA isolation kit (Invitrogen, USA). PCR was performed for amplification of the ITS region with fungal ITS specific degenerate primer (forward primer $5^{\prime}$-TCMGTAGGT GADCCWBCGS- $3^{\prime}$ and reverse primer $5^{\prime}$-TCCTNCGYTKATKGVTADGH-3') followed by amplified ITS sequence alignment with similar sequences of other fungi using the BLASTN program (NCBI, USA). Mega 6 software (Pennsylvania State University, USA) was used for the construction of the phylogenetic tree with 26 aligned sequences of fungi using maximum likelihood analysis and Tamura 3-parameter nucleotide substitution methods (Aharwar and Parihar 2019).

\section{Microbial source and growth}

Five bacterial strains were used for evaluating the antibacterial activity of fungal metabolites. These bacterial strains namely, Bacillus circulans (Gram-positive, rods MTCC-7906), Bacillus subtilis (Gram-positive, rods MTCC-441), Escherichia coli (Gram-negative rods, MTCC-739), Ralstonia eutropha (Gram-positive Rhodococcus, MTCC-2487), Staphylococcus aureus (Grampositive cocci, MTCC-96) and fungal cultures of Candida albicans (MTCC-3017), Saccharomyces cerevisiae specific mutant strain BY4742 (MTCC-3157) were procured from the microbial-type culture collection (MTCC, CSIR-IMTECH, Chandigarh, India) and used in the investigation of antimicrobial properties of the secondary fungal metabolites. All five bacterial cultures were grown overnight on Luria-Bertani agar (LB) slants and maintained at $4{ }^{\circ} \mathrm{C}$ for further experiments.

\section{Purification of ethanolic extract}

Ethanolic extract was purified to obtain active metabolites for further investigation. In brief, $1 \mathrm{~g}$ of dry extract was mixed with ethanol $(1: 1 \mathrm{w} / \mathrm{v})$ and subjected to adsorption chromatography on a glass column packed with silica gel (60-120 mesh size) in toluene. Elution was carried out by standard method with increasing polarity of toluene, chloroform, ethyl acetate, methanol, and acetonitrile. Fractions obtained from each solvent were collected and subjected to spectrophotometric evaluation and selected fractions were further concentrated by the rotatory evaporator.

\section{High-performance liquid chromatography (HPLC) analysis}

The collected extracts and fractions were used for initial screening on TLC plates. The screening sample was dissolved in $(1: 1 \mathrm{w} / \mathrm{v})$ in HPLC grade methanol. The purity of the compound was confirmed by HPLC (Shimadzu Liquid Chromatography LC10A; Shimadzu Corp., Kyoto, Japan) using a $\mathrm{C}_{18}$ analytical column. Injected sample $(20 \mu \mathrm{L})$ was eluted at a flow rate of $1 \mathrm{~mL} / \mathrm{min}$ under an isocratic mobile phase consisting of acetonitrile: water: acetic acid (18:80:2) (v/v) followed by analysis of elution profile at $280 \mathrm{~nm}$ (Shen et al. 2007).

\section{Identification of compound using spectroscopy techniques UV-visible spectroscopy}

The sample was dissolved in ethanol. The absorption maximum $(\lambda \max )$ of the purified compound was determined (UV-1800 Shimadzu spectrophotometer, Shimadzu, Kyoto, Japan) by scanning over $200-800 \mathrm{~nm}$ range to record the spectrum. 


\section{Fourier transform infrared (FTIR) spectroscopy}

The FTIR was used for functional group analysis of the sample. An infrared spectrum of purified compounds was recorded on an FTIR spectrometer (I05 Nicolet Avatar 370, Thermo Scientific, USA) at room temperature. Briefly, the purified compound (5 $\mathrm{mg}$ ) was mixed with spectroscopic grade $\mathrm{KBr}(95 \mathrm{mg})$ for pellet preparation. The IR spectrum was recorded in the transmission mode at the frequency range of $4000-400 / \mathrm{cm}$. The $\mathrm{KBr}$ pellet without sample was used as control.

\section{Gas chromatography-mass spectroscopy (GC-MS)}

GC-MS analysis of the samples was performed (Shimadzu GC-MS-QP2020; Kyoto, Japan) for qualitative and quantitative analysis using the electron impact ionization $(70 \mathrm{eV})$ method and mass spectra. The components were identified based on the comparison of their relative index and compared to the mass spectra of standards available in the GC-MS library of the National Institute of Standards and Technology (NIST; Gaithersburg, Maryland, United States). Further, the percentage of constituents was measured based on the peak area.

\section{Nuclear magnetic resonance (NMR)}

${ }^{1} \mathrm{H}$ NMR of the sample was performed on Bruker advance III $400 \mathrm{MHz}$ NMR spectrophotometer. In brief, $5 \mathrm{mg}$ of the sample was dissolved in the DMSO and centrifuged at $8000 \mathrm{rpm}$ for $10 \mathrm{~min}$ and then analyzed for ${ }^{1} \mathrm{H}$ NMR as described earlier (Morcombe and Zilm 2003). Chemical shifts were expressed in terms of parts per million (i scale) and elemental analysis was carried out at Centre for Bio-separation Technology (CBST), Vellore Institute of Technology, Vellore, India. The data were used for the putative prediction of molecular formula and structural characteristics of the active compound comparing with the standards.

\section{Bioactive properties of isolated compound}

The antioxidant and antimicrobial functional characteristics of the isolated pure compound from T. purpureogenus and extracts were evaluated in triplicates with appropriate blanks and controls (ascorbic acid for antioxidant and streptomycin for antibacterial activity) in all the experiments.

\section{2,2-Diphenyl 1-picrylhydrazyl (DPPH) activity radical scavenging activity}

The DPPH $(0.2 \mathrm{mM})$ radical scavenging activity was measured using modified method as described previously (Dhale and Vijay-Raj 2009). The activity was evaluated using various concentrations $(31.25-125 \mu \mathrm{g} / \mathrm{mL})$ of purified compound at $517 \mathrm{~nm}$ and calculated according to the formula:

$$
\text { DPPH scavenging activity }(\%)=\left[\mathrm{A}_{0}-\mathrm{A}_{30}\right] /\left[\mathrm{A}_{0}\right] \times 100,
$$

where $\left[\mathrm{A}_{0}\right]$ was the absorbance of the control (DPPH without sample) and $\left[\mathrm{A}_{30}\right]$ was the absorbance of the sample with DPPH (Barapatre et al. 2015).

\section{Ferric reducing antioxidant power (FRAP) assay}

The ferric reducing antioxidant power (FRAP) assay was determined, according to the method of Benzie and Strain (1996). Briefly, when a ferric tripyridyltriazine (Fe III-TPTZ) complex gets reduced to the ferrous (Fe II) form at low $\mathrm{pH}$, an intense blue color appears. Low $\mathrm{pH}$ is responsible for maintaining iron solubility and a decrease in the ionization potential that drives electron transfer and increases the redox potential. The FRAP activity of the sample was determined at various concentrations $(66.7-166.7 \mu \mathrm{g} / \mathrm{mL})$ by observing an increase in the absorbance values at $595 \mathrm{~nm}$.

\section{2,2'-Azino-bis3-ethylbenzthiazoline-6-sulfonic (ABTS) antioxidant assay}

ABTS (2,2'-azino-bis3-ethylbenzthiazoline-6-sulfonic) radical cation decolorization assay is based on the inhibition by antioxidants of absorbance imparted by radical cation 2,2-azinobis-(3-ethylbenzothiazoline-6-sulphonate) $\left(\mathrm{ABTS}^{*}+\right)$. Test samples were mixed with the $\mathrm{ABTS}^{*+}$ solution, incubated for $2 \mathrm{~h}$ in dark followed by observation of absorbance at $734 \mathrm{~nm}$ (Aadil et al. 2014).

\section{Phosphomolybdenum assay}

Phosphomolybdenum assay method was utilized for the spectrophotometric quantitation of total antioxidant capacity by combining the sample with $1 \mathrm{~mL}$ of reagent solution ( $0.6 \mathrm{M}$ sulfuric acid, $28 \mathrm{mM}$ sodium phosphate and $4 \mathrm{mM}$ ammonium molybdate) followed by incubation at $95{ }^{\circ} \mathrm{C}$ for $90 \mathrm{~min}$. The samples were cooled to room temperature, and the absorbance of the test solution was measured at $695 \mathrm{~nm}$ against a blank (Sowndhararajan and Kang 2013).

\section{Antimicrobial activity}

The antibacterial activity assay was carried out using disc diffusion method (Balachandran et al. 2016) against pathogenic organism Bacillus circulans (MTCC-7906), Bacillus subtilis (MTCC-441), Escherichia coli (MTCC-739), Ralstonia eutropha (MTCC-2487) and Candida albicans (MTCC-3017) as test organisms. Samples impregnated onto Whatman filter paper number 1 discs were used to determine antibacterial activity. Plates were incubated for $24 \mathrm{~h}$ at $37^{\circ} \mathrm{C}$ followed by measurement of zones of 
inhibition. Ethanol was used as vehicle control and streptomycin $(1 \mathrm{mg} / \mathrm{mL})$ as positive control.

\section{In silico analysis by molecular docking}

Molecular docking of isolated and characterized fungal metabolite, 3-methyl-4-oxo-pentanoic acid with standard anticancer and anti-aging drugs was carried out against selected target proteins to study the binding-affinity,energy, -mode and scoring functions. The structure of the targets was retrieved from the Protein Data Bank (PDB). Molecular docking and ligand-receptor interactions study was carried out using Molecular Operating Environment 2008 (moe.2008) software (Chemical Computing Group, Montreal, Canada) to investigate possible binding conformations of the receptor-ligand complex (Naik et al. 2011). For anti-aging potential the targets chosen were yeast Taf14 containing YEAST domain at N-terminus (Schulze et al. 2010) (RCSB PDB ID: 2L7E); Yeast Hsp90 chaperone N-terminal domain (Huai et al. 2005) (RCSB PDB ID: 1AH8) and Yeast protein Dre2 containing Fe-S with $\mathrm{S}$-adenosyl methionine methyl transferase-like domain (Soler et al. 2012) (RCSB PDB ID: 2KM1). Similarly, for anticancer activity, c-MYC promoter of $D U-145$, a human prostate cancer cell line (Luoto et al. 2010) (RCSB PDB ID: 6AU4); Focal Adhesion Kinase (FAK), an important mediator of cell adhesion, growth, proliferation, survival, angiogenesis, and migration, which is often disrupted in cancer cells (RCSB PDB ID:1MP8, MCF-7) (Golubovskaya 2010); vimentin coil $1 \mathrm{~A} / 1 \mathrm{~B}$ fragment together with actin filaments and microtubules, intermediate filaments (IFs), the basic cytoskeletal components of metazoan cells (Chernyatina et al. 2012) (RCSB PDB ID: 3SSU, MDA-MB-231) and VHS domain of TOM1 protein of Homo sapiens, found at the N-termini of selected proteins involved in intracellular membrane trafficking (RCSB PDB ID: 1ELK MCF-7) (Misra et al. 2000) was chosen for docking study.

\section{Anti-aging analysis}

Traditional spot assay was employed for evaluation of the anti-aging capacity of identified compounds in eukaryotic haploid organism (Yeast) Saccharomyces cerevisiae specific mutant strain BY4742 (MTCC-3157) as described earlier (Zhao et al. 2017). BY4742 strain of $S$. cerevisiae was inoculated in $5 \mathrm{~mL}$ YPD (Yeast Peptone Dextrose broth (Hi-Media, Mumbai, MH, India) and incubated overnight at $28 \pm 2{ }^{\circ} \mathrm{C}$ till exponential phase. $40 \mu \mathrm{L}$ fungal extract was spotted in the YPD agar plate, fluconazole (Nystatin) was used as negative control while culture without extract, acarbose, and rapamycin were treated as positive control. Growth of yeast strain was observed after incubation of $72 \mathrm{~h}$ at $28 \pm 2{ }^{\circ} \mathrm{C}$. Further yeast growth curve determination was also performed using the method of Wei et al. (2017): Delaney et al. (2013): Tauk tornisielo et al. (2007) with slight modification. S. cerevisiae BY 4742 inoculum was prepared using yeast dextrose peptone nutrient medium at $28^{\circ} \mathrm{C}$. $100 \mu \mathrm{L}$ of extract $(10 \mathrm{mg}$ ) was taken and $100 \mu \mathrm{L}$ of inoculum was added. Acarbose and rapamycin were taken as control. Absorbance was taken at $600 \mathrm{~nm}$ using ELISA Reader at different time points.

\section{Antiproliferative activity}

The antiproliferative activity of the extracts and fractions were determined in various tissue-specific cancer cells lines such as breast cancer ( $M D A-M B-231, M D A$ $M B-468$, and $M C F-7$ ), liver cancer (HepG2), lung cancer $(A-549)$, prostate cancer $(D U-145)$ and primary control cell line (HEK-293) by sulforhodamine B (SRB) assay as described previously (Manupati et al. 2017). Briefly, each cell line was trypsinized and plated in 96-well plate at density $5 \times 10^{3}$ cells per well. After $24 \mathrm{~h}$ incubation, cells were treated with increasing concentration $(1,10,100$ and $300 \mathrm{mg} / \mathrm{mL}$ ) of all the column fractions viz. toluene, chloroform, ethyl acetate, methanol, and acetonitrile for $48 \mathrm{~h}$ followed by fixation and SRB staining of treated cells along with respective vehicle controls. Doxorubicin was used as a positive control. The optical density at $510 \mathrm{~nm}$ was measured using a multimode reader (Perkin Elmer, Germany) and percent inhibition with IC-50 was calculated using GraphPad prism 6.0 as described previously (Manupati et al. 2019).

\section{Statistical analysis}

All assays were performed in triplicates and the results were validated statistically using one-way analysis of variance (ANOVA) followed by Tukey's multiple comparison test. All the tests were considered statistically significant at $p<0.05$. The analysis was carried out using GraphPad Prism Software Version 5.0. Results were represented as the mean \pm standard deviation $(\mathrm{SD})$.

\section{Results}

In the present work, isolated fungal strain, Talaromyces purpureogenus isolate-ABRF2 from the soil sample of Achanakmar Biosphere Reserve of Chhattisgarh forest, India, was screened for potential therapeutic secondary metabolites. Initially, we cultured the fungus in different nutrient media to identify the optimum growth conditions. The ethanolic extract of the isolated fungus Talaromyces purpureogenus isolate-ABRF2 was subjected to preliminary screening based on antioxidant and antibacterial activity. Potent crude extract (brown sticky, Fig. S1A) was further column purified based on the polarity of the solvent. Purified bioactive secondary metabolites were identified using analytical techniques such as 
UV-visible spectrophotometry, TLC, HPLC, GC-MS, and NMR. The identified bioactive metabolite, 3-methyl4-oxo-pentanoic acid (Additional file 1: Fig. S1B) was evaluated for antimicrobial, anticancer and anti-aging properties through in vitro and in silico studies.

\section{Molecular taxonomic characterization and phylogenetic analysis of fungal isolate}

The isolate, ABRF2 was morphologically characterized by cotton blue staining (Additional file 1: Fig. S2A, S2B), bright field microscopy (Additional file 1: Fig. S2C) and scanning electron microscopy (Additional file 1: Fig. S2D). It displayed white green color mycelia, with ellipsoidal conidia, thick-walled and dark red coloration, dense sporulation and plane surface colony. Colonies produce red soluble pigments on nutrient media. Molecular characterization of fungi was performed using the PCR technique, agarose gel electrophoresis and sequencing reaction with the ITS rDNA sequence. Agarose gel electrophoresis was used for the analysis of isolated genomic DNA and the PCR amplified product of the ITS region of the fungal isolate. The amplicon size of the PCR was observed to be 422 base pairs. The amplicon was sequenced and submitted to the GenBank database (NCBI accession number, MG905442). It was further analyzed for sequence similarity using the BLASTN program of NCBI. The sequence showed a maximum of $72 \%$ similarity with Talaromyces purpureogenus strain NFML_X. A phylogenetic tree was prepared by 'maximum likelihood'-a statistical method using Mega 6 software with the Tamura 3-parameter model (Substitution Model) and bootstrap method (phylogeny test). The phylogenetic tree of selected taxa was formed by the neighbor-joining method. The model used was Tamura 3-parameter with 1000 Boost strap replications. The total numbers of sites were 3555 .

\section{Structural characterization by spectroscopic methods}

The potent crude ethanolic extract and column purified fraction of isolate ABRF2 was further spotted on a silica gel TLC sheet. The components of the sample were separated by TLC and observed by visualization at UV-366 nm. Crude ethanolic extract (spot A and B) and column fractions of methanolic extract, on TLC separation, resolved to give fluorescent spots under UV light (spot D). The $R_{\mathrm{f}}$ value for spot A was observed to be 0.15 while that for spot $B$ and $C$ was found to be 0.36 . The $R_{\mathrm{f}}$ values of spot $\mathrm{D}$ was observed to be 0.41 (Additional file 1: Fig. S3). The HPLC analysis of Talaromyces purpureogenus isolate- $A B R F 2$ fungus with gradient elution
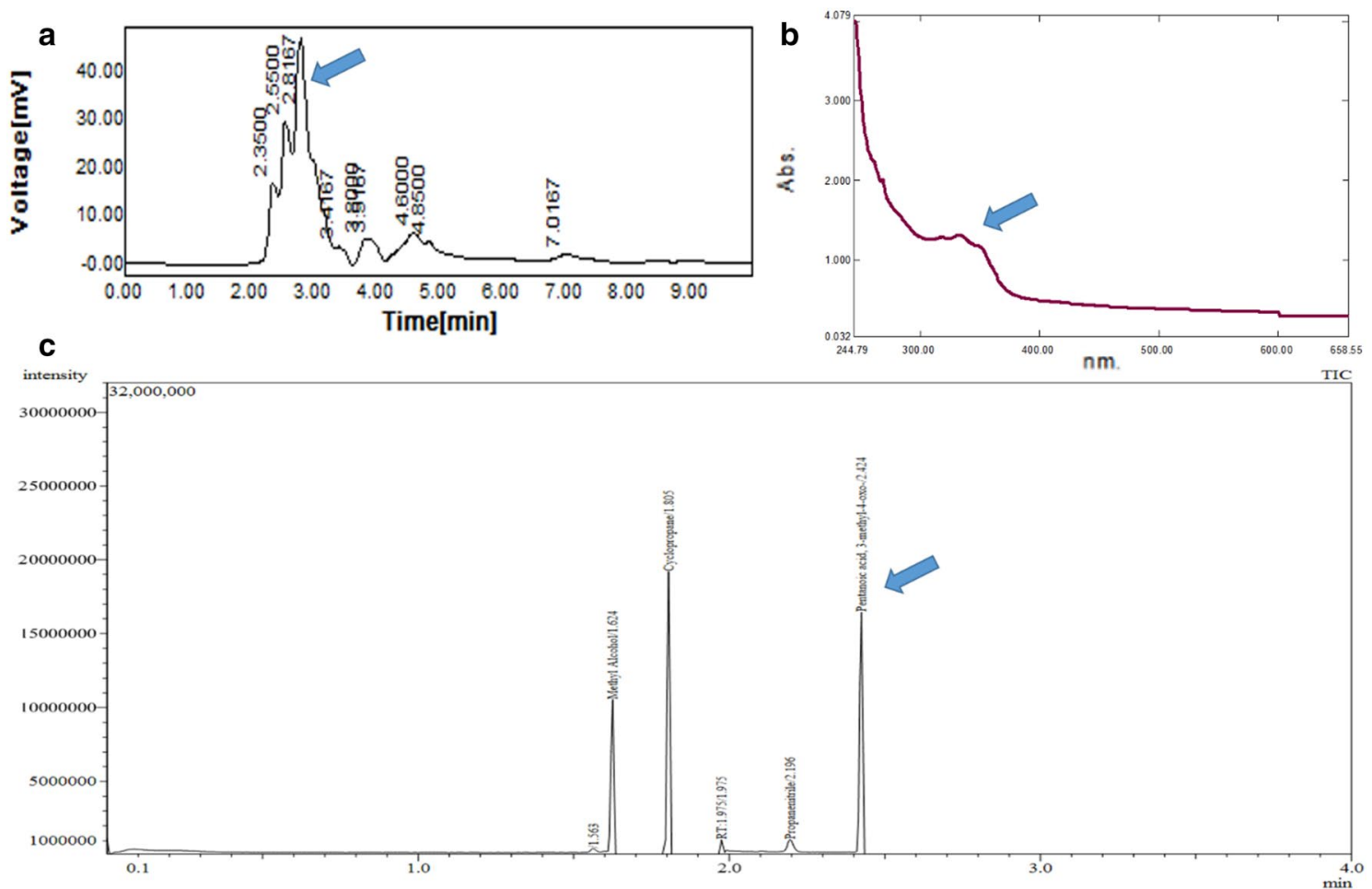

Fig. 1 Spectroscopic analysis of the purified compounds. a Purification of secondary metabolites by using HPLC. b Structural elucidation performed by UV-visible spectrophotometry. c. Depicted graph is GC-MS analysis of natural products of Talaromyces purpureogenus isolate-ABRF2 
depicted nine peaks in its ethanol extract spectra (Fig. 1a). The peaks with the following retention time ( $\mathrm{min}$ ) 2.35, $2.55,2.8167,3.4167,3.8,3.9167,4.6,4.85$ and 7.0167 were resolved. The compound of interest was eluted at Rt 2.8167. It was soluble in organic solvents including methanol, chloroform, acetone and ethanol (Fig. 1a). The structure of the selected compound was analyzed using UV-visible spectroscopy. Ethanolic fraction of fungal extract depicted absorption spectra overlapping with that of standard pentanoic acid, suggesting the isolated compound to be pentanoic acid $\left(\mathrm{C}_{5} \mathrm{H}_{10} \mathrm{O}_{2}\right)$ with absorption spectra between 300 and $400 \mathrm{~nm}$ (Fig. 1b). The purified compound when scanned over a range of $200-800 \mathrm{~nm}$, exhibited peaks between 300 and $400 \mathrm{~nm}$, suggesting the compound to be benzoic acid derivative (Fig. 1b). GCMS analysis of the ethanolic fungal extract and purified fraction showed the presence of six major peaks (Fig. 1c). The components corresponding to the peaks were determined and represented in tabular form (Additional file 1: Table S1). Pentanoic acid, 3-methyl-4-oxo- was one of the metabolites (molecular weight, $103 \mathrm{~g} / \mathrm{mol}$ ) selected to determine its biological significance while the remaining of the detected peaks/compounds corresponded to the solvents like methyl alcohol, cyclopropane, and propane nitrile with relatively out of scope for therapeutic relevance in the present study.

The column-fractionated samples were subjected to the FTIR analysis for structural elucidation of the compound. A broad range of bands (3910-3660 $\mathrm{cm}^{-1}$ ) were observed in the chloroform and ethyl acetate fraction that can be attributed to the $-\mathrm{OH}$ group stretching in phenolic and aliphatic structures and oscillation of the hydroxyl group. A characteristic peak that appeared at $3155 \mathrm{~cm}^{-1}$ represented the stretching of $-\mathrm{OH}$ group, molecular hydrogen bonding and vibration of molecules. The IR spectrum depicted the presence of an aromatic ring substituted with an ester bond thereby predicting the probable functional group present in the compound. Putative prediction of the isolated compound identified it to be a pyrone derivative (Fig. 2 and Additional file 1: Table S2). The NMR spectrum of column fraction of the compound was further evaluated for structural identification using the obtained peaks at various ' $i$ ' values of proton ${ }^{1} \mathrm{H}$ (Fig. 3). The data obtained has led us to the presumption that the antibacterial compound contains methyl, ketone, and hydroxyl functionalities. The NMR spectrum showed that the antibacterial compound has $\mathrm{CH} 2, \mathrm{CH} 3, \mathrm{OH}$, and $\mathrm{C}-\mathrm{H}$ protons functionalities while the elemental data showed the presence of carbon, hydrogen and hydroxyl group suggesting the compound to be an ester. The ${ }^{1} \mathrm{H}$ NMR spectrum of the isolated compound, 3-methyl-4-oxo-pentanoic acid corroborated well with the same number of protons as pentanoic acid
(Fig. 3). A comparative analysis of the ${ }^{1} \mathrm{H}$ NMR spectrum has been described in tabular form (Additional file 1: Table S3). This shows that the primary, secondary and tertiary aliphatic group presence of a broad peak at 0.9, 1.3 and $1.5 \delta$, respectively. The carbonyl and hydroxyl groups were intact at 2.2 and $3.5 \delta$, respectively, although some changes in chemical shifts were noticed.

\section{Antioxidant activity}

Antioxidants provide cellular defense through entrapping free radical generated by toxic metals and series of mechanisms get initiated by terminating chain reaction or chelating metal ions and reactive oxygen species or by maintaining the redox potential to stop or minimize reduction of molecular oxygen. Our findings indicate the presence of a higher concentration of potential reductones, $83 \%$ scavenging activity in YESB crude extract as compared with other extracts (Fig. 4). Hence, the FRAP reaction was correlated with the varying concentrations of the antioxidants that were observed to be reproducible (Fig. 4). The DPPH radical scavenging activity of secondary metabolites in the different medium was observed to be in the range of $18-79 \%$. However, crude extract in YESB media demonstrated the highest DPPH radical scavenging activity at $79 \%$. The activity of the crude extract was comparable to that of control, ascorbic acid. Ascorbic acid and un-inoculated media were used as positive and negative controls, respectively. Free radicals often affect the cellular macromolecules and signaling mechanisms while antioxidants protect it. We observed that YESB extract, with $80 \%$ scavenging capacity was very strong in the cation-free radical quenching compared to other extracts, thereby suggesting the presence of relative hydrophobic reductones in the latter. Formation of a bluish-green colored complex at acidic $\mathrm{pH}$ signifies the reduction of phosphomolybdate (VI) to phosphomolybdate (V) during the phosphomolybdenum assay. The highest percentage of scavenging activity of the crude extract was observed in the YESB medium (74\%), although a significant difference in scavenging activity was observed between the positive control, ascorbic acid, and crude extract (Fig. 4). Thus, these data suggest YESB extract has potent free-radical scavenging activity.

\section{Antimicrobial activity}

Column-fractionated relatively pure compounds, tested for antibacterial activity in the concentration range of $20-100 \mu \mathrm{g} / \mathrm{mL}$, inhibited the growth of $B$. circulans (MTCC-7906), B. subtilis (MTCC-441), Ralstonia eutropha (MTCC-2487), S. aureus (MTCC-96), and $E$. coli (MTCC-739) at a maximum concentration of $100 \mu \mathrm{g} / \mathrm{mL}$ in a qualitative assay (Fig. 5). Maximum activity was found in ethyl acetate column fraction with 


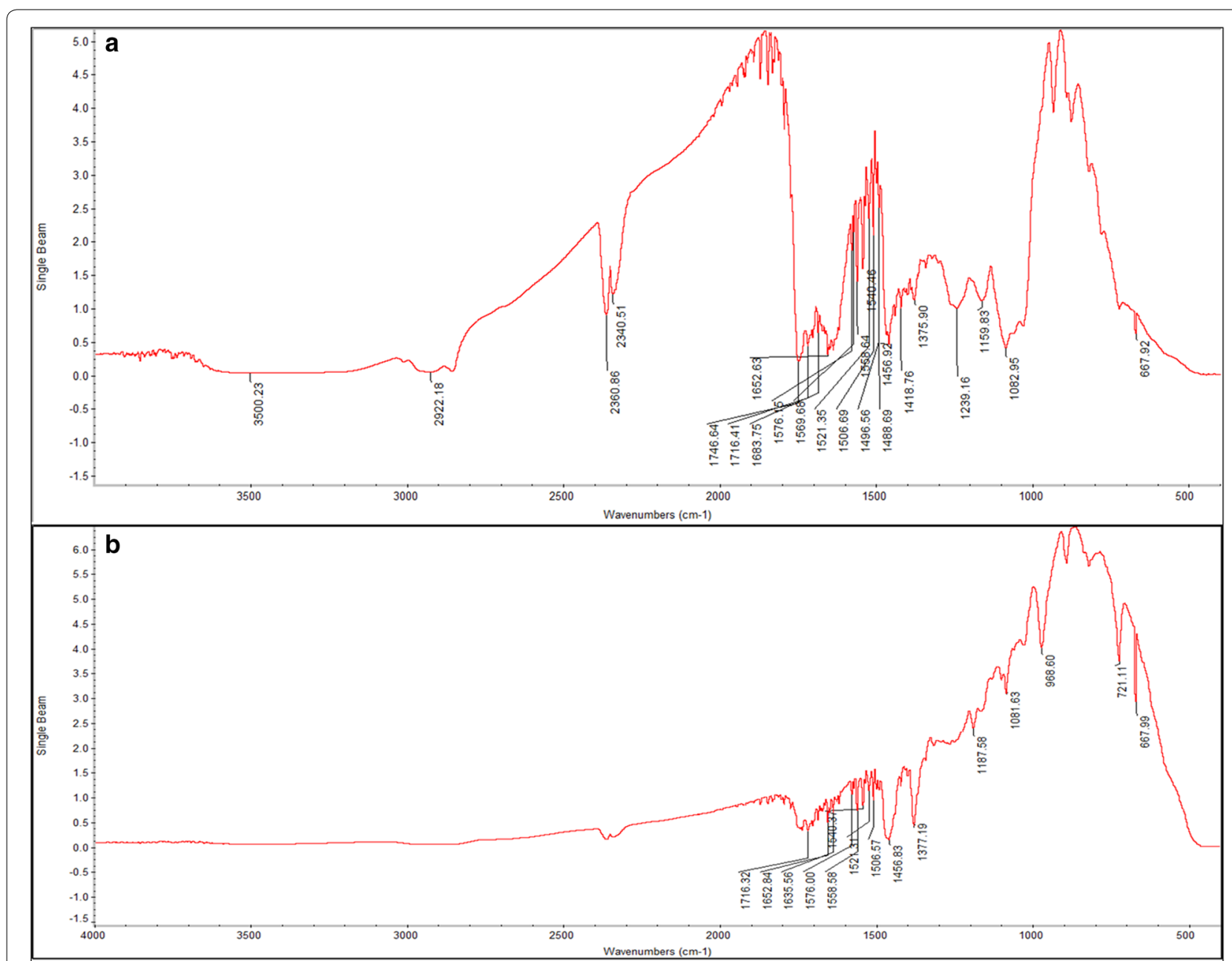

Fig. 2 FTIR analysis of the column fraction of Talaromyces purpureogenus isolate-ABRF2. a Graph represents the FTIR pattern of chloroform fraction of selected sample. $\mathbf{b}$ Graph represents the FTIR pattern of ethyl acetate fraction of selected sample

clearance zone of $19.17 \pm 1.5 \mathrm{~mm}$ against Gram-positive bacteria $B$. subtilis whereas $16.16 \pm 1.5 \mathrm{~mm}$ was observed against Gram-negative bacteria $R$. eutropha. The results were comparable to the positive control, streptomycin (Additional file 1: Table S4).

Antifungal activity of the crude fungal extract and column-fractionated sample obtained were evaluated for antifungal activity against C. albicans (MTCC-3017) (Additional file 1: Table S5). Plate depicted the zone of inhibition $(10.11 \pm 0.89)$ of acetonitrile column fraction of ethanolic extract comparable to the standard antifungal drug, fluconazole tested against $C$ albicans (MTCC-3017) (Fig. 5).

\section{Anti-aging activity}

\section{Prediction of anti-aging potential by molecular docking}

Multi-functional fungal extract regulating central cellular metabolism and metabolic pathways may serve as an effective anti-aging entrant. Therefore, molecular docking analysis was undertaken as described in the methods to dock 3-methyl-4-oxo-pentanoic acid against the chosen yeast and human anti-aging targets. The fungal metabolite, 3-methyl-4-oxo-pentanoic acid suggested the plausible role to support the growth of eukaryotic cells as demonstrated in the yeast. Slow aging may also lead to delay in carcinogenesis; reports suggest that calorie restriction affects aging by neutralizing 
a Standard<smiles>CCCCC(=O)O</smiles>

$\mathrm{N}$-Valeric acid b column fraction sample

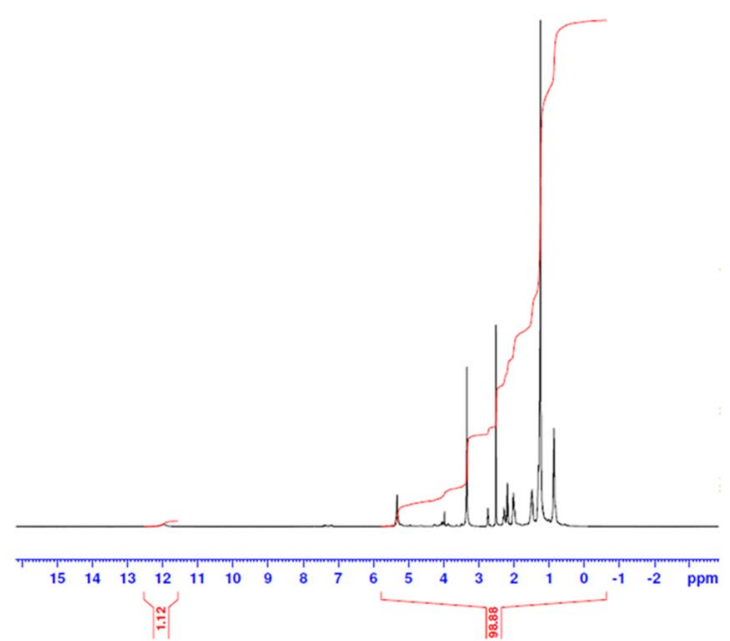

Fig. 3 NMR spectrum of column fraction of Talaromyces purpureogenus isolate-ABRF2 compared with standard. a $n$-Valeric acid or pentanoic acid as a standard. $\mathbf{b}$ Column fraction of ABRF-2 fungus strain

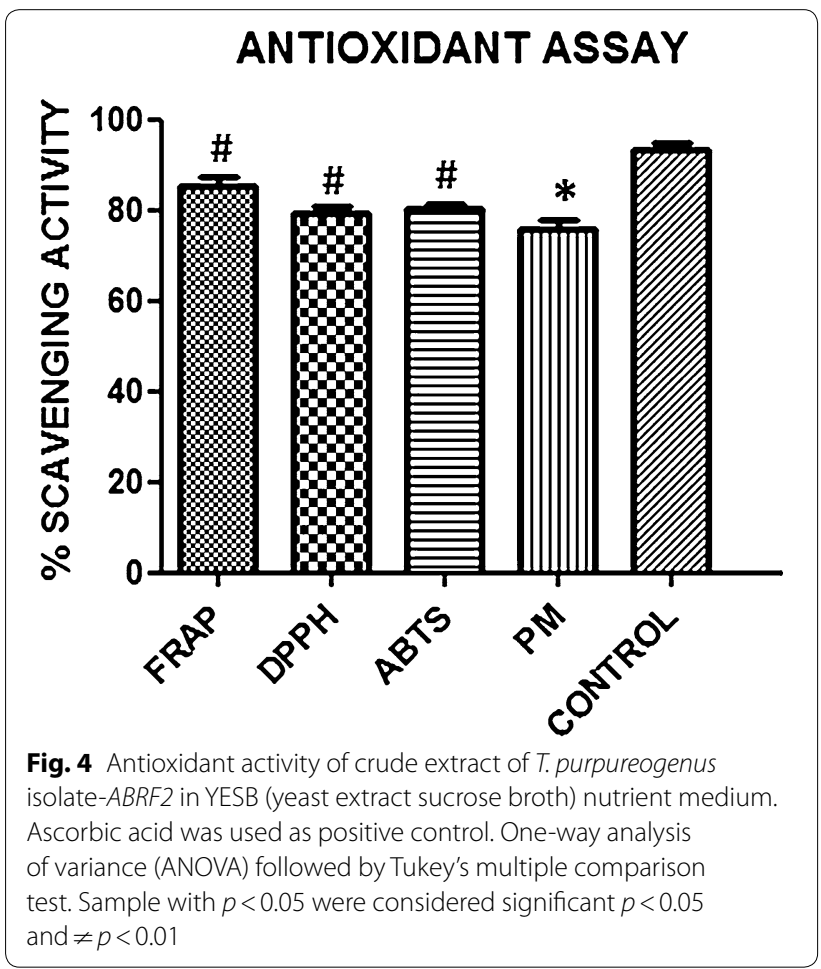

the mammalian target of rapamycin (mTOR) (Karunadharma et al. 2015). Interestingly, our observations from the in silico analysis followed by in vitro validation assays using standard drug, sirolimus (rapamycin) suggested that 3-methyl-4-oxo-pentanoic acid has a potent anti-aging property (Tables 1 and 2).

The binding energy of 3-methyl-4-oxo-pentanoic acid for site 1 of the target $1 \mathrm{AH} 8$ target, obtained from MDAMB-231 cell line, was observed to be $-14.0109 \mathrm{kCal} / \mathrm{mol}$ which was lower than standard drug, Sirolimus (rapamycin, $-12.7754 \mathrm{kCal} / \mathrm{mol}$ ), thereby suggesting a better interaction and stability of 3-methyl-4-oxo-pentanoic acid as compared with sirolimus. The presence of seven hydrogen bonds reacting with residues Lys A73, Val A74, Arg A75, Ile A54, Phe A63, Gln A206, and Glu A76 was observed. Val A74 and Val A208 were also involved in interaction through the water of hydration (Fig. 6a).

The binding energy of 3-methyl-4-oxo-pentanoic acid was observed to be $-9.9277 \mathrm{kCal} / \mathrm{mol}$ for site 8 of the target, $2 \mathrm{KM} 1$ or Yeast protein Dre2 containing $\mathrm{Fe}-\mathrm{S}$ with S-adenosyl methionine methyltransferase-like domain (RCSB PDB ID: 2KM1). However, for sirolimus (rapamycin) the binding energy was observed to be -13.4799 $\mathrm{kCal} / \mathrm{mol}$, lower than the isolated compound. Only two residues showed direct binding Leu 63 and Phe 73 (Fig. 6b).

In yeast, Taf14 containing the YEATS domain at $\mathrm{N}$-terminus (RCSB PDB ID: 2L7E) is involved in transcription (Shanle et al. 2015). The binding energy of 3-methyl4-oxo-pentanoic acid was observed to be $-9.6630 \mathrm{kCal} /$ mol for site 2 of the target 2L7E which was comparable to that of sirolimus $(-9.5644 \mathrm{kCal} / \mathrm{mol})$. Four hydrogen bonds were formed between residues Leu 86, Pro 102, Leu 108, and Gly83 (Fig. 6c). This binding analysis with 

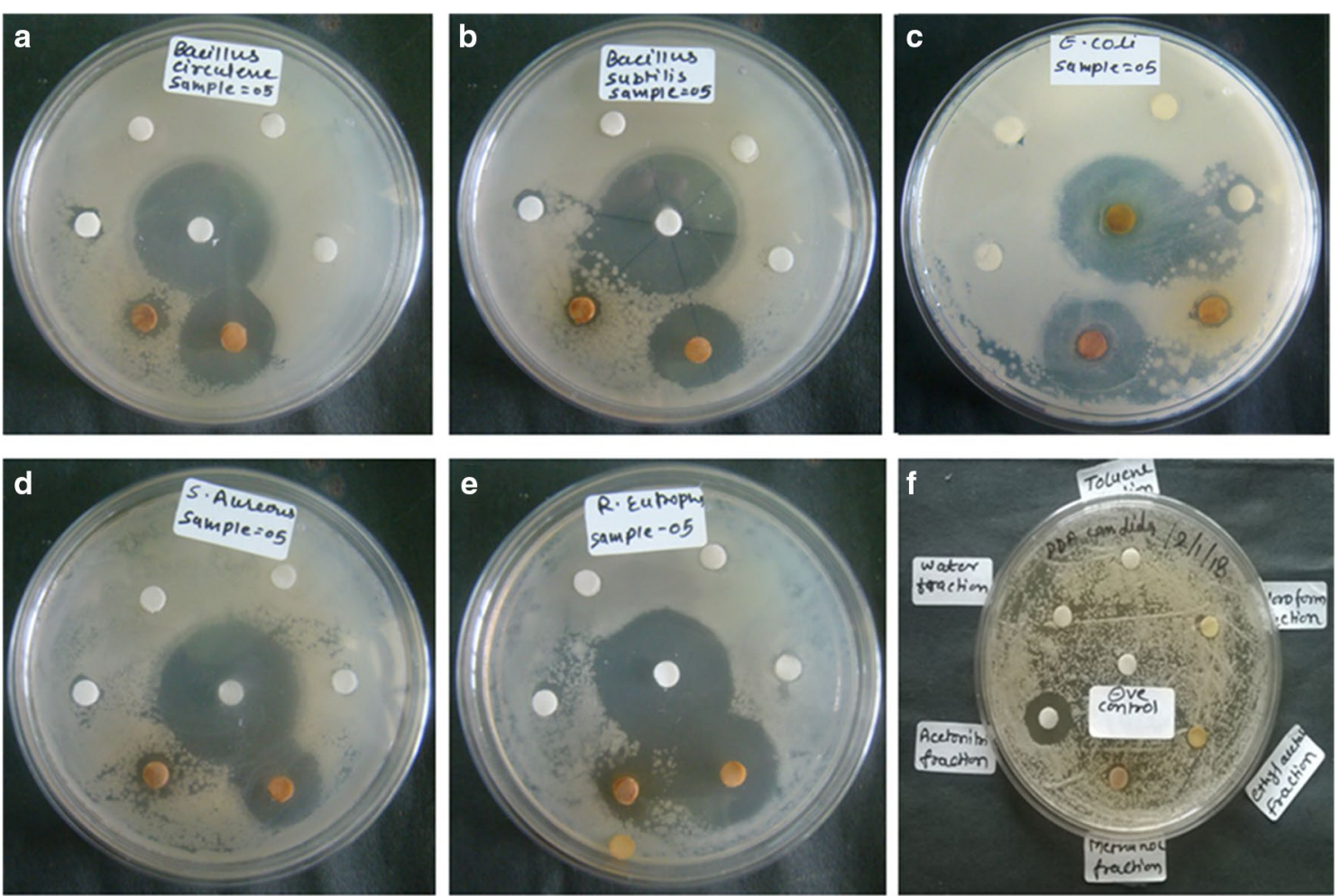

Fig. 5 Antimicrobial activity with zone of inhibition of natural products of Talaromyces purpureogenus isolate-ABRF2 against pathogenic bacterial and fungal strain. a Column fractions against Bacillus circulans. b Column fractions against Bacillus subtilis. c Column fractions against E. coli. d Column fractions against $S$. aureus. e Column fractions against $R$. eutropha. $\mathbf{f}$ Column fractions against Candida ablicans

Table 1 In silico therapeutic studies of the compound with different targets in respect of binding energy and no. of direct contacts (all polar, non-polar interactions)

\begin{tabular}{|c|c|c|c|c|}
\hline Compound name & Therapeutic studies & $\begin{array}{l}\text { Max } \\
\text { affinity } \\
\text { with site }\end{array}$ & $\begin{array}{l}\text { Binding } \\
\text { energy }(\mathrm{kCal} / \\
\text { mol) }\end{array}$ & $\begin{array}{l}\text { No. of direct contacts (all polar, non-polar } \\
\text { interactions) }\end{array}$ \\
\hline $\begin{array}{l}\text { 3-Methyl-4-oxo-pentanoic acid with 2KM1: } \\
\text { protein binding }\end{array}$ & Anti-aging study & Site- 8 & -9.9277 & Leu 63, Phe 7 \\
\hline $\begin{array}{l}\text { 3-Methyl-4-oxo-pentanoic acid with 2L7E: } \\
\text { transcription }\end{array}$ & & Site-2 & -9.6630 & Pro 102, Leu 86, Leu 108, Gly 8 \\
\hline 3-Methyl-4-oxo-pentanoic acid with $1 \mathrm{AH} 8$ & & Site-1 & -14.0109 & $\begin{array}{l}\text { Lys A73, Val A74, Arg A75, lle A54, Phe A63, Gln } \\
\text { A206, Glu A76, Val A208 }\end{array}$ \\
\hline $\begin{array}{l}\text { 3-Methyl-4-oxo-pentanoic acid with 6AU4: } \\
\text { DNA }\end{array}$ & Anticancer study & Site- 6 & -13.5751 & $\begin{array}{l}\text { DG 13, DG B8, DT B20, DG B19, DG B9, DG B4, DA } \\
\text { A22, DG B5, DG B6, DG B10, DG B13 }\end{array}$ \\
\hline $\begin{array}{l}\text { 3-Methyl-4-oxo-pentanoic acid with 1MP8: } \\
\text { transferase }\end{array}$ & & Site- 5 & -13.2413 & $\begin{array}{l}\text { Glu 506, lle 428, Leu 553, Glu 430, Glu 500, Cys } \\
\text { 502, Lys 454, Gly 431, Gln 432, Phe 433, Asp } \\
\text { 564, Glu471, Leu 501, Ala 452, Val 436, Gly } 429\end{array}$ \\
\hline 3-Methyl-4-oxo-pentanoic acid with 3SSU & & Site-1 & -7.7187 & $\begin{array}{l}\text { Glu A187, Asp A181, Arg A184, Lys A188, Leu } \\
\text { A189, Met A183, lle A182 }\end{array}$ \\
\hline 3-Methyl-4-oxo-pentanoic acid with 1ELK & & Site-4 & -15.2661 & $\begin{array}{l}\text { Val A59, Arg A 57, Val A54, Leu A51, Asp A93, Ala } \\
\text { A53 }\end{array}$ \\
\hline
\end{tabular}

different amino acids of the target sites suggested that the compound 3-methyl-4-oxo-pentanoic acid to be a potential regulator of different anti-aging pathways.

\section{Spot assay and yeast growth curve}

To validate the anti-aging activity, spot assay was performed with Saccharomyces cerevisiae specific mutant 
Table 2 Table representing comparison between binding energy of anti-aging and anticancer targets and to identify the probable mechanism of action

\begin{tabular}{|c|c|c|c|c|c|c|c|}
\hline \multirow[t]{3}{*}{ Molecule } & \multicolumn{7}{|c|}{ Targets used for molecular docking } \\
\hline & \multicolumn{3}{|c|}{$\begin{array}{l}\text { Binding energy }(\mathrm{kCal} / \mathrm{mol}) \text { of different targets } \\
\text { for anti-aging molecular docking }\end{array}$} & \multicolumn{4}{|c|}{$\begin{array}{l}\text { Binding energy }(\mathrm{kCal} / \mathrm{mol}) \text { of different targets for anticancer } \\
\text { molecular docking }\end{array}$} \\
\hline & 2L7E (Site 2) & 2KM1 (Site 8) & $1 \mathrm{AH} 8$ (Site 1) & 6AU4 (Site 6) & $1 \mathrm{MP8}$ (Site 5) & 3SSU (Site 1) & 1ELK (Site 4) \\
\hline Doxorubicin & -12.6052 & -16.4337 & -30.5751 & -15.4418 & -21.9661 & -10.5860 & -29.5353 \\
\hline Metformin & -9.3988 & -10.1731 & -10.2898 & -11.3161 & -9.0020 & -6.2210 & -9.7292 \\
\hline Noscapine & -12.0867 & -15.2318 & -22.3027 & -11.9761 & -19.1626 & -8.6372 & -18.8927 \\
\hline Sirolimus & -9.5644 & -13.4799 & -12.7754 & -8.0782 & -12.8416 & -8.9583 & -12.1555 \\
\hline $\begin{array}{l}\text { 3-Methyl-4-oxo- } \\
\text { pentanoic acid }\end{array}$ & -9.6630 & -9.9277 & -14.0109 & -13.5751 & -13.2413 & -7.7187 & -15.2661 \\
\hline
\end{tabular}

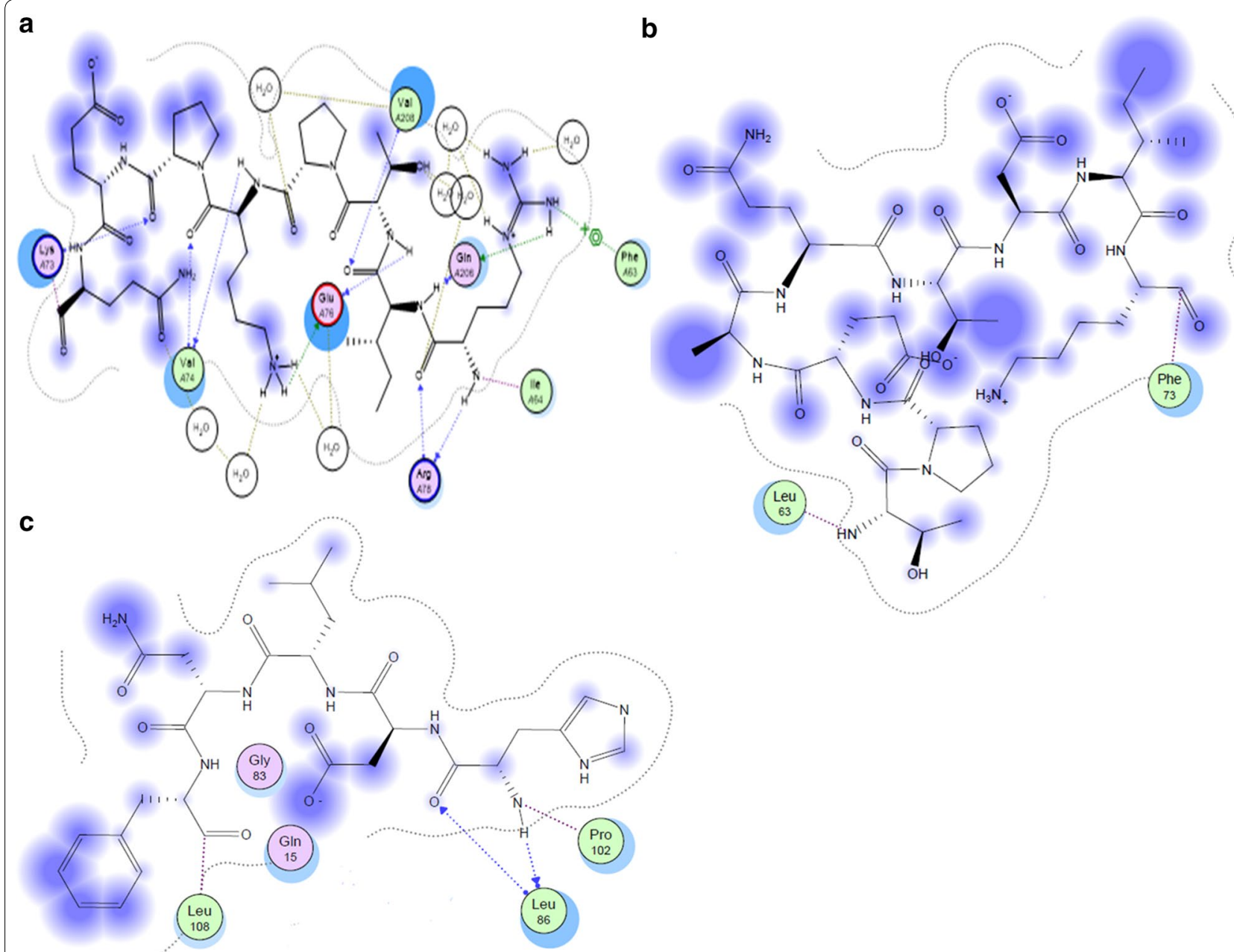

Fig. 6 Molecular docking of the compound pentanoic acid with anti-aging targets. a 2-D diagram of 1AH8 residues interacting with compound 3-methyl-4-oxo-pentanoic acid forming polar contacts with the ligands and residues showing in lines participating in other interactions. $\mathbf{b}$ 2-D diagram of 2KM1: protein binding interacting with compound 3-methyl-4-oxo-pentanoic acid. c 2L7E: transcription interacting with compound 3-methyl-4-oxo-pentanoic acid

strain BY4742 (MTCC-3157) (Zhao et al. 2017). Negative control, nystatin and positive control, acarbose and/or 

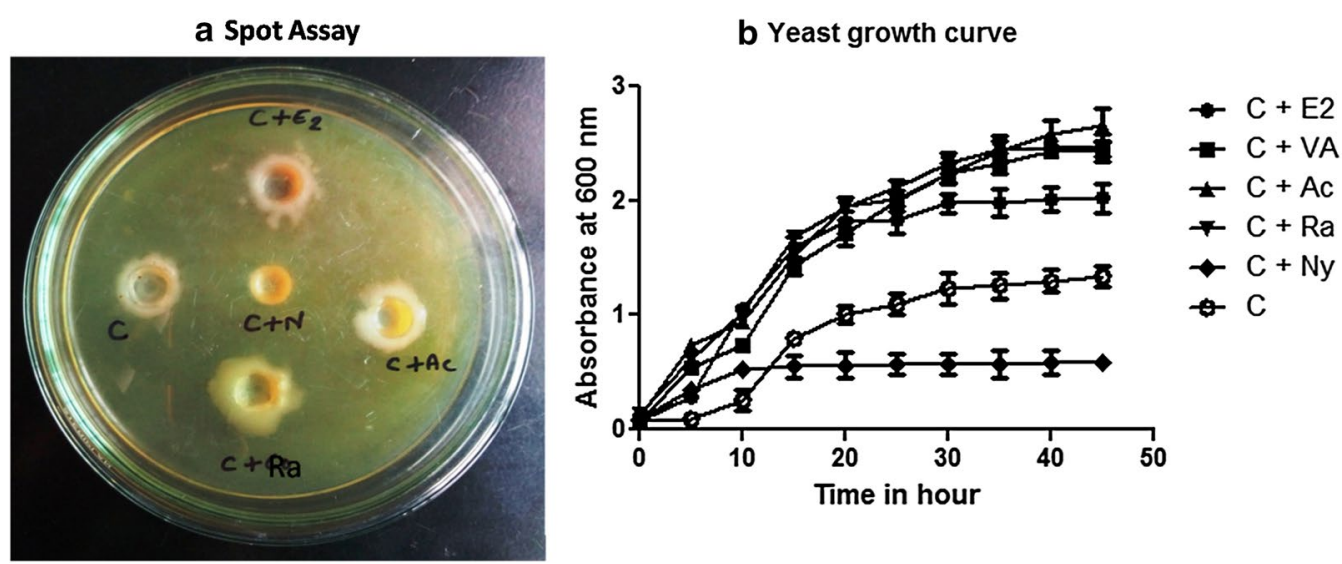

Fig. 7 In vitro spot assay of anti-aging activity of the crude extract of secondary metabolites of Talaromyces purpureogenus isolate-ABRF2. S. cerevisiae BY4742 cells spotted onto YPD plates. Growth curve for the S. cerevisiae BY4742 strain were measured in YPD medium. $p<0.05$ indicated a significant difference. Fungal extract and their growth spots generated during spot assay along with control systems using S. cerevisiae BY4742. C - culture only (S. cerevisiae BY4742); C +E2 — culture and extract of isolate ABRF2; C+N-culture and fluconazole (nystatin) as negative control; $\mathrm{C}+\mathrm{VA}$-culture and $n$-valeric acid; $\mathrm{C}+\mathrm{Ac}$-culture and acarbose and C+Ra—culture and rapamycin as positive control

rapamycin $(1 \mathrm{mg} / \mathrm{mL})$ were used in the experiment. The fungal extract showed a spot diameter of $12 \pm 0.46 \mathrm{~mm}$ while the positive controls, acarbose, and rapamycin depicted $15 \pm 0.87$ and $17 \pm 0.94 \mathrm{~mm}$, respectively, in the study using S. cerevisiae BY4742 (Fig. 7a and Additional file 1: Table S6). The growth signifies the putative antiaging effect of 3-methyl-4-oxo-pentanoic acid through the calorie restriction pathway. Furthermore, yeast growth curve depicted an increased exponential phase in the culture having ABRF2 extract as compared with the positive controls, acarbose, and rapamycin as well as and negative control, nystatin (Fig. 7b).

\section{Antiproliferative activity}

Prediction of anticancer potential by molecular docking The docking interaction of the isolated compound, 3-methyl-4-oxo-pentanoic acid against, c-MYC was performed as described in the methods to identify and predict the binding site residues. The docked ligand molecules were selected based on the interaction with the active site residues and lowest docking energy. The presence of a total of five hydrogen bonds with binding sites of 3-methyl-4-oxo-pentanoic acid, including two hydrogen bonds formed by the Lys 62 were observed. The other three hydrogen bonds were observed to be formed by the residues Asn 108, Thr 102 and Ile 103, respectively (Fig. 8). The compound also interacted with Asn 61, Glu 44, Arg 84 and Asn 41 through the water of hydration. The binding energy was observed to be -13.5751 $\mathrm{kCal} / \mathrm{mol}$ for site 6 of $6 \mathrm{AU} 4$ from the c-MYC of DU-145. Compound, 3-methyl-4-oxo-pentanoic acid was most potent with a higher docking score of $-11.4592 \mathrm{kCal} /$ mol, compared to that of the standard drug, doxorubicin $(-10.088 \mathrm{kCal} / \mathrm{mol})$. These findings confirm the plausible role of 3-methyl-4-oxo-pentanoic acid as an anticancer agent that can be evaluated in the future with the mechanism of action for potential drug development. The in vitro cytotoxic assay further confirmed the observed in silico activity of 3-methyl-4-oxo-pentanoic acid, with $\mathrm{IC}_{50}$ value at a low micromolar range of the 3-methyl-4-oxopentanoic acid fraction against DU-145 of $2.36 \pm 0.156$, thereby suggesting potential antiproliferative/anticancer activity of the isolated compound (3-methyl-4-oxo-pentanoic acid) (Table 4).

The docking of compound against the anticancer site- 5 on 1MP8, a well-known target of MCF-7, depicted a total of five hydrogen bonding with the residues Glu 506, Glu 500, Cys 502, Lys 454, Gln 432. The isolated compound also interacted with Glu 430, Ile 428, Leu 553, Lys 454, Phe 433 and Asp 564 through the water of hydration. The binding energy was observed to be $-13.2413 \mathrm{kCal} /$ mol for site 5 of 1MP8: transferase from the MCF-7 which was lower than that of the potent anticancer drug, doxorubicin with docking score of $-21.29661 \mathrm{kcal} / \mathrm{mol}$ (Fig. 8a).

1ELK of the VHS domain of TOM1 protein reported as target in MCF-7 cancer cell line is involved in the degradation of growth factor receptor complexes through their translocation to the lysosome. The binding energy of the compound, 3-methyl, 4-oxo-pentanoic acid was $-15.2661 \mathrm{kCal} / \mathrm{mol}$ for site 4 of the target 1 ELK on MCF-7 breast cancer cell line as compared to the maximum affinity and lowest binding energy score of $-29.5353 \mathrm{kCal} / \mathrm{mol}$ for doxorubicin. Direct binding via 

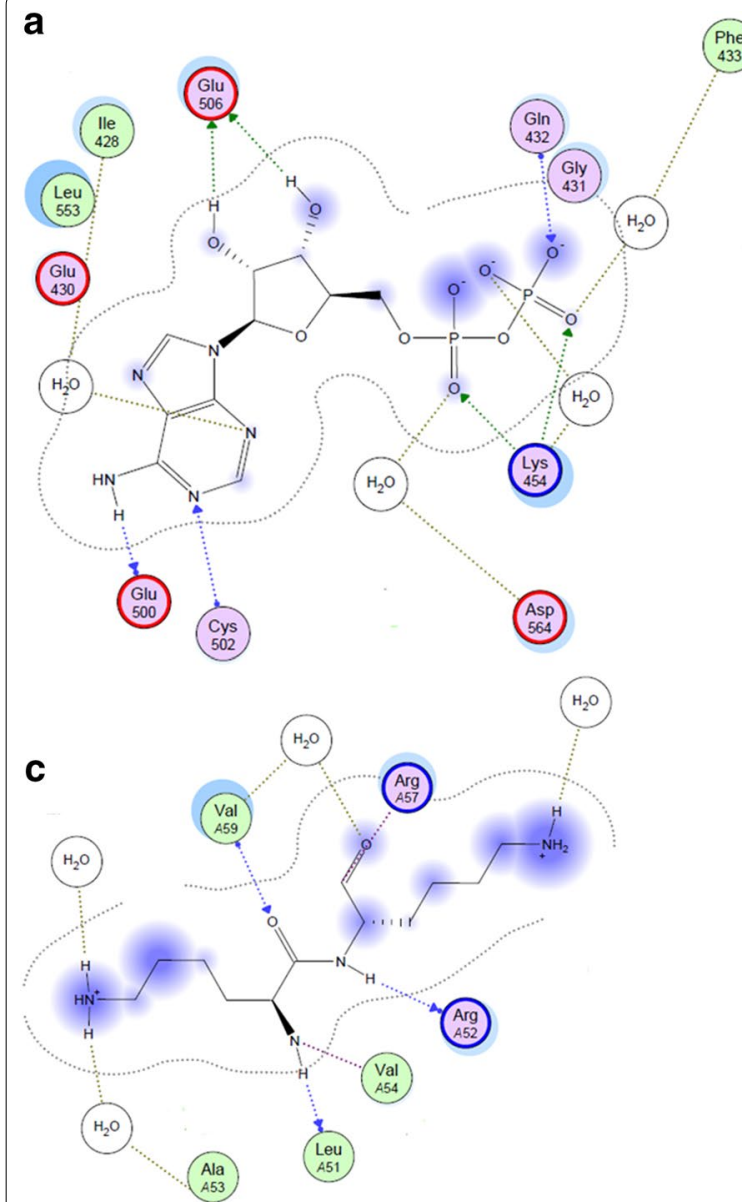

Asp b

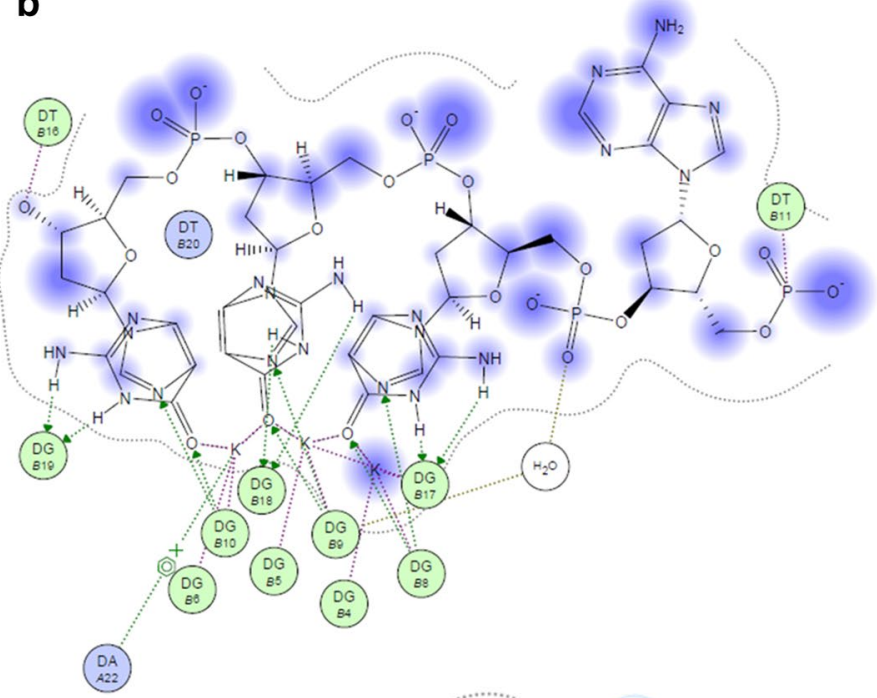

d

Fig. 8 Molecular docking and interaction of the compound pentanoic acid to the different anticancer cell line targets. a 3-Methyl-4-oxo-pentanoic acid with 1MP8: transferase. Interact with structure of the cancer-related Focal Adhesion Kinase (FAK) and molecule. b 3-Methyl-4-oxo-pentanoic acid with 1ELK. Interaction of 1ELK (MCF-7) VSH domain of TOM 1 (target of myb 1) protein from Homo sapiens with molecule. c

3-Methyl-4-oxo-pentanoic acid with 6AU4: DNA. Interaction with crystal structure of the major quadruplex formed in the human c-MYC promoter and molecule. $\mathbf{d}$ 3-Methyl-4-oxo-pentanoic acid with 3SSU. Interaction between crystal structure of vimentin central helical domain and its implications for intermediate filament assembly 3SSU (MDA MB 231) and obtained molecule

hydrogen bonds with Val A59, Arg A57, Val A54, Leu A51, and Ala A53 was observed. Compound has displayed two hydrogen bonds with Val A59 and Asp A93 (Fig. 8b).
Similarly, site- 1 of the 3SSU target from the MDAMB-231 cell line displayed the highest docking with compound by three hydrogen bonding with Glu A187, Asp A181, and Arg A184. The binding energy of the isolated compound was observed to be $-7.7187 \mathrm{kCal} /$

Table $3 I_{50}(\mu \mathrm{g} / \mathrm{mL})$ value of different extracts of isolate ABRF-2 (Talaromyces purpureogenus)

\begin{tabular}{llllll}
\hline $\begin{array}{l}\text { Fungal extract } \\
\text { Talaromyces purpureogenus isolate-ABRF2 }\end{array}$ & $\mathbf{I C}_{\mathbf{5 0}}(\boldsymbol{\mu \mathbf { g }} / \mathbf{m L})$ & & & & \\
\cline { 2 - 7 } & $\mathbf{M C F - 7}$ & MDA-MB-231 & DU-145 & HEPG2 & A549 \\
\hline Extracellular secondary metabolites & $181.25 \pm 14.12$ & $749.75 \pm 28.95$ & $366.85 \pm 0.72$ & $1807.5 \pm 375.57$ & $39,795 \pm 16,532.42$ \\
Intracellular secondary metabolites & $134.26 \pm 22.08$ & $181.4 \pm 34.81$ & $122.55 \pm 4.94$ & $830.45 \pm 1.13$ & $1081 \pm 8.67$ \\
Ethanolic extract & $\mathrm{Nl}$ & $\mathrm{Nl}$ & $2.36 \pm 0.15$ & $26,395 \pm 5702.49$ & $\mathrm{Nl}$ \\
\hline
\end{tabular}


mol for site 1 of the target 3SSU of MDA-MB-231 cell line as compared to $-10.5860 \mathrm{kCal} / \mathrm{mol}$ for doxorubicin (Fig. 8c). These binding affinities of the molecule with different amino acids of the target sites propose that the compound 3-methyl-4-oxo-pentanoic acid may act as a therapeutic potential drug on different anticancer pathway.

\section{In vitro antiproliferative activity}

To determine the antiproliferative activity of the crude fungal extract were further purified and segregated as extracellular and intracellular extracts to localize the selected metabolites. All three types of extracts were tested against tissue-specific cancer cell lines, using $\mathrm{SRB}$ assay as described in the methods. Intracellular extracts demonstrated lower $\mathrm{IC}_{50}$ values and thus higher cytotoxicity (Table 3 ). The extract was further purified by adsorption column chromatography. The fractions were assessed for antiproliferative activity. Fraction $\mathrm{A}$ and $\mathrm{C}$ (toluene and ethyl acetate fraction) depicted more antiproliferative potential against breast cancer, MCF-7 and liver cancer, HepG2 cell line with $\mathrm{IC}_{50}$ of 2.79 and $2.75 \mu \mathrm{g} / \mathrm{mL}$ as compared with the positive control (doxorubicin) with $\mathrm{IC}_{50}$ of 5.06 and $1.65 \mu \mathrm{g} /$ $\mathrm{mL}$, respectively. $M D A-M B-468$ was observed to be highly sensitive with fraction $B\left(\mathrm{IC}_{50}<0.35 \mu \mathrm{g} / \mathrm{mL}\right)$ suggesting these fractions might contain efficacious anticancer lead molecules which can be further isolated, identified and purified as they did not show any comparable toxicity in normal primary cells $(H E K-293)$ (Table 4). However, toluene and ethyl acetate fraction was also observed to be highly potent against liver cancer, but toluene fraction had similar toxicity in cancer as well as non-cancerous (control) cells with $\mathrm{IC}_{50}$ of 2.75 and $2.29 \mu \mathrm{g} / \mathrm{mL}$, respectively. Similarly, the antiproliferative potential of fraction $\mathrm{C}$ (ethyl acetate fraction) containing 3-methyl 4-oxo-pentanoic acid was observed to be comparable with cancer and normal cells.

\section{Discussion}

Identified fungus Talaromyces purpureogenus isolate$A B R F 2$ from the Achanakmar Biosphere Reserve forest of central India was characterized based on the morphological parameters such as variation in shape and size of fungal spores and hyphae (Wyatt et al. 2013; Gautier et al. 2016). The analysis of phenotypic characteristics and spore structure forms the major identifying principle in fungi. The preliminary identification was corroborated by sequence analysis of the ITS region of the strain. Talaromyces purpureogenus isolate- $A B R F 2$ fungus was grown on Yeast Extract Sucrose Broth media (YESB) under optimized incubation condition. Both the intracellular and extracellular secondary metabolites were extracted and screened for therapeutic potential, the intracellular secondary metabolites depicted higher potential compared to extracellular and hence, the isolated intracellular compound was further evaluated. Successive Soxhlet extraction of $50 \mathrm{~g}$ dry biomass resulted in $0.45,0.67,1.2,4.8$ and $2.7 \mathrm{~g}$ dry extract, respectively, for solvents diethyl ether toluene, chloroform, ethanol, and acetonitrile. The ethanolic extract was selected and

Table 4 Assessment of cytotoxic profile of column chromatography fractions against various tissue-specific cancer

\begin{tabular}{|c|c|c|c|c|c|c|c|}
\hline \multirow[t]{2}{*}{ Fungal fractions } & \multicolumn{7}{|l|}{$I C_{50}(\mu \mathrm{g} / \mathrm{mL})$} \\
\hline & MCF-7 ${ }^{\mathbf{b}}$ & MDA-MB-468 & MDA-MB-231 & $\mathrm{DU}-145^{\mathrm{e}}$ & HEPG- ${ }^{f}$ & A549g & HEK-293 ${ }^{\text {h }}$ \\
\hline Fraction A & $2.79 \pm 1.69$ & $7.71 \pm 2.44$ & $40.29 \pm 11.95$ & $9.46 \pm 0.09$ & $2.75 \pm 0.53$ & $103.89 \pm 64.04$ & $293.35 \pm 1.59$ \\
\hline Fraction B & $\mathrm{NI}$ & $0.34 \pm 0.28$ & $\mathrm{NI}$ & $\mathrm{NI}$ & $\mathrm{NI}$ & $\mathrm{NI}$ & $\mathrm{NI}$ \\
\hline Fraction C & $7.04 \pm 2.11$ & $3.38 \pm 1.33$ & $5.95 \pm 2.95$ & $\mathrm{NI}$ & $7.08 \pm 5.6$ & $21.58 \pm 18.09$ & $9.2 \pm 3.4$ \\
\hline Fraction D & $27.29 \pm 14.7$ & $3.57 \pm 0.29$ & $11.06 \pm 1.83$ & $28.58 \pm 1.84$ & $119.2 \pm 1.75$ & $125.59 \pm 51.47$ & $\mathrm{NI}$ \\
\hline Fraction E & $30.37 \pm 3.23$ & $3.41 \pm 1.12$ & $5.41 \pm 0.71$ & $\mathrm{NI}$ & $24.20 \pm 19.38$ & $52.43 \pm 4.66$ & $59.28 \pm 15.23$ \\
\hline Fraction F & $32.06 \pm 12.61$ & $9.36 \pm 4.72$ & $\mathrm{NI}$ & $0.43 \pm 0.35$ & $\mathrm{NI}$ & $\mathrm{NI}$ & $\mathrm{NI}$ \\
\hline Doxorubicin & $5.06 \pm 0.72$ & $0.65 \pm 0.15$ & $0.30 \pm 0.06$ & $0.018 \pm 0.007$ & $1.65 \pm 1.55$ & $3.35 \pm 0.54$ & $70.45 \pm 8.12$ \\
\hline
\end{tabular}

NI: no inhibition; Fraction A: toluene; B: chloroform; C: ethyl acetate; D: methanol, E: acetonitrile, F: water

a $50 \%$ inhibitory concentrations and mean \pm SEM of $\mathrm{IC}_{50}(\mu \mathrm{g} / \mathrm{mL})$ values of different fractions represent the mean of three individual experiments

b Luminal-A (ER+/PR+/Her2-) breast cancer

c Basal (low claudin) triple-negative (ER-/PR-/Her2-) breast cancer

d Basal triple-negative (ER-/PR-/Her2-) breast cancer

e Moderate metastatic potential (PSA+) androgen-independent prostate cancer

f Liver hepatocellular carcinoma

9 Adenocarcinoma human alveolar basal epithelial cells lung cancer

h Non-cancerous primary human embryonic kidney cells 
subjected to column chromatography, obtaining $1.7 \mathrm{~g}$ of purified active component.

The isolated secondary metabolites showed various characteristic features. The $R_{\mathrm{f}}$ value of Spots $\mathrm{B}, \mathrm{C}$, and $\mathrm{D}$ ranged from 0.30 to 0.40 which corresponds to valeric acid, or 3-methyl-4-oxo-pentanoic acid with $R_{\mathrm{f}}=0.49$ (Hassan et al. 2008; Singh et al. 2006). 3-methyl-4-oxopentanoic acid is a straight-chain alkyl carboxylic acid sesquiterpenoid constituent of the essential oil of the valerian plant. Further, the presence of 3-methyl-4-oxopentanoic acid was confirmed using various spectral analysis. UV absorbance at $\lambda \max 272$ and $328 \mathrm{~nm}$ having the typical pattern of 3-methyl-4-oxo-pentanoic acid. The IR spectrum showed absorption bands at 1716.32, 1652.84 and $1181.53 \mathrm{~cm}^{-1}$ revealed the similarity with 3-methyl-4-oxo-pentanoic acid reported earlier in the literature suggesting biotransformation of pyrone to benzoic acid and derivatives by microorganisms (Parshikov et al. 2015). The GC-MS analysis of a crude extract of ABRF2 revealed the presence of ester compound, which when further validated by ${ }^{1} \mathrm{H}$ NMR, showed chemical shift similar to standard $n$-valeric acid/pentanoic acid.

Antioxidants are molecules useful in reducing the free radicals produced by oxidative stress and managing the cellular network. Clinical data suggest a correlation between the pathogenesis of disease with a high level of iron in the body (Siah et al. 2006). In the Fenton reaction, ferrous ions play an important role, catalyzing the production of hydroxyl radicals and hydroxyl anions from hydrogen peroxide (Liochev and Fridovich 1999). In our present study, FRAP values of YESB crude extract were relatively higher and comparable to standard ascorbic acid. FRAP values are based on reducing ferric ion with antioxidants as the reducing agent, higher FRAP value indicating greater antioxidant capacity (Fernandes et al. 2016). DPPH scavenging activity of YSEB extract from isolate $A B R F 2$ was similar to the reported T. purpureogenus CFRM02 extracts (Pandit et al. 2018). The variation in the structure and different functional groups present in the molecules led to differences in the antioxidant activity across different methods. The metabolic processes, irradiation and oxidative processes may lead to the formation of primary ROS which then react with biomolecules forming secondary ROS (Loganayaki et al. 2013). These free radicals damage macromolecules and cellular components, however, antioxidants protect biomolecules. $\mathrm{ABTS}^{+}$scavenging capacity represents freeradical scavenging efficiency in a hydrophilic medium (Re et al. 1999). Our data showed that $\mathrm{ABTS}^{+}$activity was slightly lower than FRAP but higher than DPPH activity. Phosphomolybdate assay is a routine method for estimating the reducing capacity of plant-derived antioxidants (Prieto et al. 1999). Interestingly, we observed the lowest activity of our compound in phosphomolybdate assay as compared with other antioxidant assays that were comparable with control, L-ascorbic acid.

The secondary metabolites of Talaromyces sp. predominantly containing esters including, linear polyesters are known to show various biological activities, including antibacterial actions (Zhai et al. 2016). The results obtained in the present study are comparable to the standard antibiotic streptomycin (Sarker et al. 2007). We observed a differential growth inhibition pattern of gram-positive by the ethyl acetate fraction containing the compound, 3-methyl, 4-oxo-pentanoic acid. Similarly, the zone of inhibition against gram-negative bacteria, $R$. eutropha was observed to be similar to that reported earlier of Alternaria sp (Palanichamy et al. 2018). Interestingly, antifungal activity against candida albicans was not observed in the ethyl acetate fraction.

The outcome of the initial pharmacokinetic studies of the isolated compound, 3-methyl-4-oxo-pentanoic acid incited us to further explore the anti-aging and anticancer activity. Literature suggests that $1 \mathrm{AH} 8,2 \mathrm{KM} 1$ and 2L7E are the targets associated with transcription and translational modification in eukaryotic system and are linked to the process of aging. Interestingly, the same signaling molecules have been shown to be involved and targeted for cancer therapy (Blagosklonny 2012). Rapamycin slows down aging, suppresses cellular senescence, and postpone age-related diseases (Blagosklonny 2012). Further to validate the anti-aging activity, we employed specific spot assay with eukaryotic model organism Saccharomyces cerevisiae mutant strain BY4742 (MTCC3157) as reported earlier (Zhao et al. 2017). Using the method of Wei et al. (2017), we observed that in the presence of $A B R F 2$ crude extract, the formation of growth zone by yeast was higher in size as compared with control suggesting it's potential to enhance the lifespan and delay aging of yeast cell. In yeast growth curve determination, $A B R F 2$ crude extract significantly enhanced the yeast growth exponential phase and delayed the aging process similar to the positive control. Anti-aging results suggested that fungal extracts have putative compounds responsible for the enhancement of cell life.

The c-MYC oncogene is often dysregulated or overexpressed in multiple tumor cell survival pathways (Stump et al. 2018). One of the major targets of anticancer compounds is the DNA quadruplex formed in the NHE III1 region of the c-MYC promoter. Antitumor small molecules tend to stabilize this quadruplex thereby reducing c-MYC expression (Stump et al. 2018). These observations were further validated using in vitro antiproliferative activity against a variety of tissue-specific cancer cell lines that demonstrated potent antiproliferative activity 
specifically against breast cancer $M C F-7$ and liver cancerHepG2 cell lines.

\section{Conclusion}

Talaromyces purpureogenus isolate- $A B R F 2$ crude extract and column-fractionated samples demonstrated modest antioxidant activity combined with antibacterial activity. The extract and fractions were subjected to GC-MS and NMR, leading to the identification of 3-methyl-4-oxopentanoic acid. In silico molecular docking analyses against anti-aging and anticancer targets of isolated compounds depicted higher binding energy as compared with standard drugs. Thus, the compound 3-methyl4-oxo-pentanoic acid isolated from Talaromyces purpureogenus isolate- $A B R F 2$ with antioxidant and anticancer (cytotoxic) activities is a potential candidate for drug development.

\section{Supplementary information}

Supplementary information accompanies this paper at https://doi. org/10.1186/s40643-020-00303-z.

Additional file 1. Methods, data on identification and biological activity profile of fungi and isolated active secondary metabolite.

\section{Abbreviations}

ABRF: Achanakmar Biosphere Reserve Fungus; FRAP: Ferric reducing antioxidant power; DPPH: 2,2-Diphenyl 1-picrylhydrazyl; ABTS: 2,2'-Azinobis3-ethylbenzthiazoline-6-sulfonic; PM: Phosphomolybdenum; GC-MS: Gas chromatography-mass spectroscopy; NMR: Nuclear magnetic resonance; LB: Luria-Bertani agar; CDB: Czapek Dox broth; CDYB: Czapek Dox yeast broth; MEB: Malt extract broth; PDB: Potato dextrose broth; TLC: Thin-layer chromatography; HPLC: High-performance liquid chromatography; FTIR: Fourier transform infrared spectroscopy; NIST: National Institute of Standards and Technology; CBST: Centre for Bio-separation Technology; Fe III-TPTZ: Ferric tripyridyltriazine; PDB: Protein Data Bank; MOE: Molecular Operating Environment; FAK: Focal adhesion kinase; IF: Intermediate filaments; SRB: Sulforhodamine B assay.

\section{Acknowledgements}

The authors are thankful to the Department of Biotechnology, Guru Ghasidas Vishwavidyalaya for providing necessary facilities to carry out the research work. Fellowship provided by UGC-SRF to KK is gratefully acknowledged. Dr. Sanjit Kumar, Centre for Bio-separation Technology, VIT Vellore, for NMR analysis, Prof. Pradeep Naik, Sambalpur University, Odisa and Miss Sharmishtha Pal are acknowledged for help in molecular docking analysis. Manuscript Communication Number: IICT/Pubs./2019/180.

\section{Authors' contributions}

MKS carried out the isolation of the fungus and extraction of the secondary metabolites, performed the antibacterial, antioxidant assay, anti-aging experiment, structural characterization and collaborated in the analysis of the obtained results. MKS also drafted the work. KK performed cytotoxicity and collaborated in the data interpretation. AD contributed to the analysis of different characterization results and also with the writing and revision of the draft. $\mathrm{HJ}$ is the corresponding author who provided the idea for the realization of this work. $\mathrm{HJ}$ also contributed to the data interpretation and the revision of the draft. All authors read and approved the final manuscript.

\section{Funding}

The work was supported by UGC SAP project no. F.3-14/2016/DRS-I (SAP-II). $A D$ acknowledges the funding provided by DBT, Government of India, Cancer Pilot Project, and Sanction No. 6242-P65/RGCB/PMD/DBT/AMTD/2015.

\section{Availability of data and materials}

All data generated or analyzed during this study are included in this research article.

\section{Ethics approval and consent to participate}

Not applicable.

\section{Consent for publication}

Not applicable.

\section{Competing interests}

The authors declared no conflict of interest. Presented work does not include any studies with human participants or animals performed.

\section{Author details}

${ }^{1}$ Department of Biotechnology, Guru Ghasidas Vishwavidyalaya, Bilaspur, Chhattisgarh 495009, India. ${ }^{2}$ Department of Applied Biology, CSIR-Indian Institute of Chemical Technology, Uppal Road, Tarnaka, Hyderabad, TS 500 007 , India. ${ }^{3}$ Academy of Scientific and Innovative Research (ACSIR), CSIR-IICT Campus, Hyderabad, India.

Received: 13 January 2020 Accepted: 11 March 2020

Published online: 18 March 2020

\section{References}

Aadil KR, Barapatre A, Sahu S, Jha H, Tiwary BN (2014) Free radical scavenging activity and reducing power of Acacia nilotica wood lignin. Int J Biol Macromol 67:220-227

Aharwar A, Parihar DK (2019) Talaromyces verruculosus tannase production, characterization and application in fruit juices detannification. Biocatal Agric Biotechnol 18:101014

Badri DV, Weir TL, Lelie D, Vivanco JM (2009) Rhizosphere chemical dialogues: plant-microbe interactions. Curr Opin Biotechnol 20:642-650

Baker DD, Alvi KA (2004) Small-molecule natural products: new structures, new activities. Curr Opin Biotechnol 15:576-83

Balachandran C, Duraipandiyan V, Arun Y, Sangeetha B, Emi N, Dhabi NA, Ignacimuthu S, Inaguma Y, Okamoto A, Perumal PT (2016) Isolation and characterization of 2-hydroxy-9, 10-anthraquinone from Streptomyces olivochromogenes (ERINLG-261) with antimicrobial and antiproliferative properties. Revista Brasileira de Farmacognosia 26:285-295

Barapatre A, Aadil KR, Tiwary BN, Jha H (2015) In vitro antioxidant and antidiabetic activity of biomodified Acacia wood lignin. Int J BiolMacromol 75:81-89

Benzie IF, Strain JJ (1996) The ferric reducing ability of plasma (FRAP) as a measure of "antioxidant power": the FRAP assay. Anal Biochem 239:70-76

Blagosklonny MV (2012) Rapalogs in cancer prevention: anti-aging or anticancer? Cancer Biol Ther 13:1349-1354

Chernyatina AA, Nicolet S, Aebi U, Herrmann H, Strelkov SV (2012) Atomic structure of the vimentin central a-helical domain and its implications for intermediate filament assembly. PNAS 109:13620-13625

Delaney JR, Ahmed U, Chou A (2013) Stress profiling of longevity mutants identifies Afg 3 as a mitochondrial determinant of cytoplasmic mRNA translation and aging. Aging Cell 12:156-166

Dhale MA, Vijay-Raj AS (2009) Pigment and amylase production in Penicillium sp NIOM-02 and its radical scavenging activity. Int J Food Sci Technol 44:2424-2430

Fernandes RPP, Trindade MA, Tonin FG, Lima CG, Pugine SMP, Munekata PES, Lorenzo JM, Melo MP (2016) Evaluation of antioxidant capacity of 13 plant extracts by three different methods: cluster analyses applied for selection of the natural extracts with higher antioxidant capacity to replace synthetic antioxidant in lamb burgers. J Food Sci Technol 53:451-460

Gangadevi V, Muthumary J (2008) Taxol, an anticancer drug produced by an endophytic fungus Bartalinia robillardoides Tassi, isolated from a 
medicinal plant, Aegle marmelos Correa ex Roxb. World J Microbiol Biotechnol 24:717-724

Gautier M, Normand AC, Ranque S (2016) Previously unknown species of Aspergillus. Clin Microbiol Infect 22:662-669

Golubovskaya VM (2010) Focal adhesion kinase as a cancer therapy target. Anticancer Agents Med Chem 10:735-741

Hassan E, Tayebeh R, Samaneh ET, Zeinalabedin BS, Vahid N, Mehdi Z (2008) Quantification of valeric acid and its derivatives in some species of valeriana L. cantranthus longiflorus stev. Asian J Plant Sci 7:195-200

Huai Q, Wang H, Liu Y, Kim HY, Toft H, Ke H (2005) Structures of the N-terminal and middle domains of E. coli Hsp90 and Conformation Changes upon ADP Binding. Structure 13:579-590

Karunadharma PP, Basisty N, Dai DF, Chiao YA, Quarles EK, Hsieh EJ, Crispin D, Bielas JH, Ericson NG, Beyer RP, MacKay VL, MacCoss MJ, Rabinovitch PS (2015) Subacute calorie restriction and rapamycin discordantly alter mouse liver proteome homeostasis and reverse aging effects. Aging Cell 14:547-557

Kwon BK, Liu J, Messerer C, Kobayashi NR, McGraw J, Oschipok L, TetzlaffW (2002) Survival and regeneration of rubrospinal neurons 1 year after spinal cord injury. Proc Natl Acad Sci U S A. 99:3246-3251

Liochev SI, Fridovich I (1999) Superoxide and iron: partners in crime. IUBMB Life 48:157-161

Loganayaki N, Siddhuraju P, Manian S (2013) Antioxidant activity and free radical scavenging capacity of phenolic extracts from Helicteres isora $\mathrm{L}$. and Ceiba pentandra L. J Food Sci Technol 50:687-695

Luoto KR, Meng AX, Wasylishen AR, Zhao H, Coakley CL, Penn LZ, Bristow RG (2010) Tumor cell kill by c-MYC Depletion: role of MYC-regulated genes that control DNA double-strand break repair. Cancer Res 21:8748-8759

Maheshwari S, Miller MS, O'Meally R, Cole NR, Amzel LM, Gabelli SB (2017) Kinetic and structural analyses reveal residues in phosphoinositide 3-kinase a that are critical for catalysis and substrate recognition. J Biol Chem 292:13541-13550

Manupati K, Dhoke NR, Debnath T, Yeeravalli R, Guguloth K, Saeidpour S, De UC, Debnath S, Das A (2017) Inhibiting epidermal growth factor receptor signaling potentiates mesenchymal-epithelial transition of breast cancer stem cells and their responsiveness to anticancer drugs. FEBS 」 284:1830-1854

Manupati K, Debnath S, Goswami K, Bhoj PS, Chandak HS, Bahekar SP, Das A (2019) Glutathione S-transferase omega 1 inhibition activates JNK-mediated apoptotic response in breast cancer stem cells. FEBS J. https://doi. org/10.1111/febs. 14813

Maritim AC, Sanders RA, Watkins JB (2003) Diabetes, oxidative stress, and antioxidants: a review. J Biochem Mol Toxicol 17:24-38

Miranda H, Simão R, Santos Vigário P, Salles BF, Pacheco MT, Willardson JM (2010) Exercise order interacts with rest interval during upper-body resistance exercise. J Strength Cond Res 24:1573-1577

Misra S, Beech BM, Hurley JH (2000) Structure of the VHS domain of human Tom1 (target of myb 1): insights into interactions with proteins and membranes. Biochemistry 39:11282-11290

Morcombe CR, Zilm KW (2003) Chemical shift reference in MAS solid-state NMR. J Magn Reson 162:479-486

Naik PK, Santoshi S, Rai A, Joshi HC (2011) Molecular modeling and competition binding study of Br-noscapine and colchicine provide insight into noscapinoid-tubulin binding site. J Mol Graph Model 29:947-955

Nikoletti R, Lopez-Gresa MP, Manzo E, Carella AA, Clavatta ML (2007) Production and fungitoxic activity of Sch 642305, a secondary metabolite of Penicillium canescens. Mycopathologia 163:295-301

Nishihara K, Kanemori M, Yanagi H, Yura T (2000) Overexpression of trigger factor prevents aggregation of recombinant proteins in Escherichia coli. Appl Environ Microbiol 66:884-889

Palanichamy P, Krishnamoorthy G, Kannan S, Marudhamuthu M (2018) Bioactive potential of secondary metabolites derived from medicinal plant endophytes. Egypt J Basic Appl Sci. 5:303-312

Pandit S, Puttananjaih MH, Harohally N, Dhale MA (2018) Functional attributes of a new molecule- 2-hydroxymethyl-benzoic acid 2'-hydroxy-tetradecyl ester isolated from Talaromyces purpureogenus CFRM02. Food Chem 30:89-96

Parshikov IA, Woodling KA, Sutherland JB (2015) Biotransformations of organic compounds mediated by cultures of Aspergillus niger. Appl Microbiol Biotechnol 99:6971-6986

Prieto P, Pineda M, Aguilar M (1999) Spectrophotometric quantitation of antioxidant capacity through the formation of a phosphomolybdenum complex: specific application to the determination of vitamin E. Anal Biochem 269:337-341

Radhika KP, Rodrigues BF (2010) Arbuscular mycorrhizal fungal diversity in some commonly occurring medicinal plants of Western Ghats, Goa region. J Forest Res 21:45-52

Re R, Pellegrini N, Proteggente A, Pannala A, Yang M, Rice-Evans C (1999) Antioxidant activity applying an improved ABTS radical cation decolorization assay. Free Radic Biol Med 26:1231-1237

Sarker SD, Nahar L, Kumarasamy Y (2007) Microtitre plate-based antibacterial assay incorporating resazurin as an indicator of cell growth, and its application in the in vitro antibacterial screening of phytochemicals. Methods 42:321-324

Schulze JM, Kane CM, Ruiz-Manzano A (2010) The YEATS domain of Taf14 in Saccharomyces cerevisiae has a negative impact on cell growth. Mol Genet Genomics 283:365-380

Shanle EK, Andrews FH, Meriesh H, McDaniel SL, Dronamraju R, DiFiore JV, Jha D, Wozniak GG, Bridgers JB, Kerschner JL, Krajewski K, Martín GM, Morrison AJ, Kutateladze TG, Strahl BD (2015) Association of Taf14 with acetylated histone $\mathrm{H} 3$ directs gene transcription and the DNA damage response. Genes Dev 29:1795-1800

Shen HY, Jiang HL, Mao HL, Pan G, Zhou L, Cao YF (2007) Simultaneous determination of seven phthalates and four parabens in cosmetic products using HPLC-DAD and GC-MS methods. J Sep Sci 30:48-54

Siah CW, Ombiga J, Adams LA, Trinder D, Olynyk JK (2006) Normal iron metabolism and the pathophysiology of iron overload. Clin Biochem Rev. 27:5-16

Singh N, Gupta AP, Singh B, Kaul VK (2006) Quantification of valerenic acid in Valeriana jatamansi and Valeriana officinalis by HPTLC. Chromatographia 63:209-213

Soler N, Craescu CT, Gallay J, Frapart YM, Mansuy D, Raynal B, Baldacci G, Pastore A, Huang ME, Vernis L (2012) An S-adenosylmethionine methyltransferase-like domain within the essential, Fe-S-containing yeast protein Dre2. FEBS J 279:2108-2119

Sowndhararajan K, Kang SC (2013) Free radical scavenging activity from different extracts of leaves of Bauhinia vahlii Wight \& Arn. Saudi J Biol Sci 20:319-325

Stump S, Mou T, Sprang SR, Natale NR, Beall HD (2018) Crystal structure of the major quadruplex formed in the promoter region of the human c-MYC oncogene. PLOS ONE 12:13

Wei SC, Levine JH, Cogdill AP, Zhao Y, Anang NAS, Andrews MC, Sharma P, Wang J, Wargo JA, Pe'er D, Allison JP (2017) Distinct cellular mechanisms underlie Anti-CTLA-4 and anti-PD-1 checkpoint blockade. Cell 170(6):1120-1133

Wyatt TT, Wösten HA, Dijksterhuis J (2013) Fungal spores for dispersion in space and time. Adv Appl Microbiol 85:43-91

Zhai MM, Jiang CX, Shi YP, Di DL, Crews P, Wu QX (2016) The bioactive secondary metabolites from talaromyces species Nat. Prod. Bioprospect 6:1-24

Zhao W, Zheng HZ, Zhou T, Hong XS, Cui HJ, Jiang ZW, Chena H, Zhou ZJ, Liu XZ (2017) CTT1 overexpression increases the replicative lifespan of MMS-sensitive Saccharomyces cerevisiae deficient in KSP1. Mech Ageing Dev 164:27-36

\section{Publisher's Note}

Springer Nature remains neutral with regard to jurisdictional claims in published maps and institutional affiliations. 